\title{
Young Ichthyologist Award 2011 and Best Article Award 2011
}

The Ichthyological Society of Japan (ISJ) presented the Young Ichthyologist Award 2011 to Dr. Hiroyuki Motomura (Kagoshima University) for his outstanding research activities on taxonomy and zoogeography of marine and freshwater fishes. The following two papers were selected for the Best Article Award 2011.

Matsumoto S, Kon K, Yamaguchi M, Takeshima H, Yamazaki Y, Mukai T, Kuriiwa K, Kohda M, Nishida M (2010) Cryptic diversification of the swamp eel Monopterus albus in East and Southeast Asia, with special reference to the Ryukyuan populations. Ichthyological Research 57(1):71-77.

Miyashita T (2010) Unique occipital articulation with the first vertebra found in pristigasterids, chirocentrids, and clupeids (Teleostei: Clupeiformes: Clupeoidei). Ichthyological Research 57(2):121-132.

Dr. Hiroyuki Motomura gave a commemorative lecture entitled "Taxonomic studies on tropical and subtropical fishes in the Indo-Pacific Ocean" on 30 September 2011 during the ISJ annual meeting in Hirosaki, Aomori. He and the authors of the Best Article Award 2011 papers (Dr. Takeshi Kon of Toho University, and Dr. Takehiro Miyashita of Kansai Ohkura High School) received the commemorative certificates of merit from the ISJ President, Dr. Akira Goto. 